\title{
Patient-reported satisfaction and cosmesis outcomes following laparoscopic adrenalectomy: Laparoendoscopic single-site adrenalectomy vs. conventional laparoscopic adrenalectomy
}

\author{
Shogo Inoue, MD; Kenichiro Ikeda, MD; Kanao Kobayashi, MD; Mitsuru Kajiwara, MD; Jun Teishima, MD; \\ Akio Matsubara, MD
}

Department of Urology, Hiroshima University Graduate School of Biomedical Sciences, Hiroshima, Japan

Cite as: Can Urol Assoc J 2014;8(1-2):e20-5. http://dx.doi.org/10.5489/cuaj.1543

Published online January 14, 2014.

\section{Abstract}

Introduction: We evaluate patient-reported satisfaction and cosmesis of laparoendoscopic single-site adrenalectomy (LESS-A) in comparison with that of conventional laparoscopic adrenalectomy (CLA). Methods: A total of 19 and 104 patients who respectively underwent LESS-A and CLA between May 1996 and June 2011 were included in the study. Questionnaires inquiring about scar pain (0: not painful, 10: very painful), satisfaction (0: not satisfied, 10: very satisfied) and cosmesis (0: very unsightly, 10 : very beautiful) on the basis of a visual analogue scale were sent to patients postoperatively.

Results: The respondents consisted of 11 and 54 patients who underwent LESS-A and CLA, respectively. There was no significant inter-group difference in age, sex, affected side or body mass index. No significant differences were observed in operative time or estimated blood loss. There were also no significant differences in pain (0.67 vs. $0.57, p=0.393)$, satisfaction (8.92 vs. 8.46, $p=0.453$ ), or cosmesis score (8.58 vs. 8.00, $p=0.487$ ) between the LESS-A and CLA groups overall. In female patients, the satisfaction score was significantly higher in the LESS-A group than in the CLA group (10.0 vs. $8.72, p=0.049)$. In young patients $(<50$ years old), the satisfaction score was also significantly higher in the LESS-A group than in the CLA group (9.17 vs. 6.38, $p=0.036$ ). Conclusions: Young patients and female patients who had received LESS-A adrenal surgery were more satisfied with the scar outcomes than were the young patients and female patients who had received CLA. We suggest that this patient subset most values the cosmetic benefits of LESS-A.

\section{Introduction}

Laparoscopic adrenalectomy has been a standard procedure since the early 1990s for most patients with surgical adrenal tumour. ${ }^{1}$ The conventional laparoscopic adrenalectomy
(CLA) uses 3 or 4 ports, most commonly $112-\mathrm{mm}$ and 2 or 35 - $\mathrm{mm}$ ports. In recent years, there has been a paradigm shift in the field of minimally invasive surgery as laparoscopy progresses toward scarless techniques. With the advent of novel multichannel single ports as well as curved and articulating instruments, the possibility of complex laparoscopy through a single incision has been reported. Since the initial report of urologic laparoendoscopic single-site (LESS) surgery in $2007,{ }^{2}$ the number of LESS surgeries has substantially increased. Over the last few years, there has been an increasing enthusiasm and growing interest in this novel minimally invasive surgical technique. ${ }^{3}$ LESS surgery has been done for various urological diseases involving adrenal tumour, and studies of prospective outcomes show less pain, shorter hospital stays and excellent cosmetic outcomes. ${ }^{4-9}$

However, evaluation of LESS surgery cosmesis has largely entailed subjective operator assessment ${ }^{3,10-13}$ with objective evaluations limited by small sample sizes and evaluation as a secondary endpoint. ${ }^{14,15}$ Also, with regard to LESS adrenalectomy (LESS-A), the cosmesis outcome was largely based on the transumbilical approach rather than the subcostal approach. LESS-A through an umbilical access can be extremely challenging due to the angle of approach and the difficulty in retracting organs; therefore, it is usually performed using the subcostal approach. Nevertheless, the cosmesis outcome in subcostal LESS-A has rarely been reported.

We report for the first time patient-reported satisfaction and cosmesis outcomes in Japanese patients undergoing subcostal LESS-A in comparison with CLA.

\section{Methods}

\section{Patients}

Between November 2009 and June 2011, 19 consecutive patients with adrenal tumour (13 primary aldosteronism, 4 
preclinical Cushing syndrome, 2 Cushing syndrome and 1 pheochromocytoma) underwent transperitoneal LESS-A by 2 surgeons (AM and $\mathrm{SI}$ ) at Hiroshima University Hospital. We mailed questionnaires inquiring about scar pain (0: not painful, 10: very painful), satisfaction (0: not satisfied, 10 : very satisfied) and cosmesis (0: very unsightly, 10 : very beautiful) on the basis of a visual analogue scale. As a control, we sent the same survey to 104 patients who underwent CLA between May 1996 and June 2011 at Hiroshima University Hospital. This survey was carried out with institutional review board approval.

\section{Surgery}

Under general anaesthesia, patients were placed in the $60^{\circ}$ modified flank position. A 2-cm skin incision and an access into the peritoneal cavity were made by open laparotomy between the arcus costalis of the ipsilateral side and the umbilicus. Then, a multichannel port (SILS port, Covidien, Mansfield, MA) was inserted. An additional 5-mm port was used for right-sided adrenal tumours for liver retraction. ${ }^{10}$ To minimize instrument collision, a flexible $5-\mathrm{mm} 0^{\circ}$ highdefinition laparoscope (Olympus, Tokyo, Japan) was used. Pneumoperitoneum was induced by $\mathrm{CO}_{2}$ gas insufflation to $8 \mathrm{mmHg}$.

The surgical strategy followed the conventional transperitoneal adrenalectomy. ${ }^{16}$ Specifically, the Toldt's line and the typical vascular landmarks (inferior vena cava and renal vein for right- and left-sided adrenal tumours, respectively) were dissected and exposed using a bent laparoscopic instrument (Roticulator Endo Dissect, Covidien, Mansfield, MA) and straight standard instruments. The adrenal veins were identified, controlled with 25 -mm polymer locking clips (Hem-oLok, Teleflex Medical, Research Triangle Park, NC), 1 proximally and 1 distally, and then divided. A 5-mm LigaSure (Covidien, Mansfield, MA) was also used to complete the adrenal gland dissection. After hemostasis was ensured, the entire adrenal gland containing the tumour was freed within the abdomen and placed in an Endo Catch Gold specimen pouch (Covidien, Mansfield, MA) and inserted through the exchanged 12-mm channel. The specimens were retrieved together with the SILS port without any further skin incision in all cases. A surgical suction drain was left in place through the surgical port. All procedures were performed transperitoneally; the CLA procedure was the same as the LESS-A procedures except for the access port.

\section{Statistical analysis}

The survey data were analyzed according to surgical approach using the chi-square test and the Mann-Whitney $U$ test. Each analysis performed was two-tailed, with a $p$ value $<0.05$ considered statistically significant. To evaluate the cosmesis and satisfaction with the scar after laparoscopic adrenalectomy, we applied the logistic regression model. Analyses were performed using JMP version 10 statistical software package (SAS Institute Inc., Cary, NC).

\section{Results}

\section{Demographics}

There was no conversion to open surgery in any of the patients who underwent LESS. One case of LESS-A, however, was converted to CLA by placing 3 additional trocars and was therefore excluded from this study. For the remaining 18 patients, LESS-A was completed successfully without any intraoperative complications. In all cases, the insertion of the SILS port was easily performed.

Out of the 19 LESS-A patients, 11 (6 men, 5 women) completed the survey (57.9\%). Out of the 104 CLA patients, 54 (25 men, 29 women) completed the survey (51.9\%). The mean patient age was 52.3 (range: $35-69$ ) years and the body mass index (BMI) was 23.4 (range: 20.7-26.7) (Table 1). The mean follow-up times after surgery were 12.1 (range: $5-19$ ) and 64.3 (range: 18-181) months for the LESS-A and CLA groups, respectively $(p<0.001)$. There was no significant inter-group difference in age, male-to-female ratio, affected side or BMI. No significant differences were observed in the operative time (206.2 vs. $177.0 \mathrm{~min}, p=0.228$ ) or estimated blood loss (18.2 vs. $100.4 \mathrm{~mL}, p=0.548)$.

\section{Cosmesis outcome}

There were no significant differences in overall pain $(0.67$ vs. $0.57, p=0.393$ ), satisfaction (8.92 vs. $8.46, p=0.453$ ) or cosmesis score (8.58 vs. 8.00, $p=0.487$ ) between the LESS-A and CLA groups (Fig. 1). However, in female patients, the satisfaction score was significantly higher in the LESS-A group than in the CLA group (10.0 vs. 8.72, $p=0.049$ ) (Fig.

Table 1. Patient characteristics

\begin{tabular}{lccc}
\hline & LESS-A (n=11) & CLA ( $\mathbf{n = 5 4 )}$ & $\boldsymbol{p}$ value \\
\hline Age, years, mean (range) & $52.3(35-69)$ & $56.6(29-86)$ & 0.280 \\
Gender, male:female & $6: 5$ & $25: 29$ & 0.618 \\
Laterality, right:left & $5: 6$ & $18: 36$ & 0.444 \\
Body mass index, mean & 23.4 & 23.3 & 0.951 \\
(range) & $(20.7-26.7)$ & $(16.5-36.3)$ & \\
Operative time, minutes, & 206.2 & 177.0 & 0.228 \\
mean (range) & $(124-360)$ & $(90-415)$ & \\
Estimated blood loss, & $18.2(10-40)$ & 100.4 & 0.548 \\
mL, mean (range) & \multicolumn{4}{c}{$(5-3270)$} \\
$\begin{array}{l}\text { Follow-up time, months, } \\
\text { mean (range) }\end{array}$ & $12.1(5-19)$ & $(18-181)$ & $<0.001$ \\
\hline LESS-A: laparoendoscopic single-site adrenalectomy; CLA: conventional laparoscopic \\
adrenalectomy.
\end{tabular}




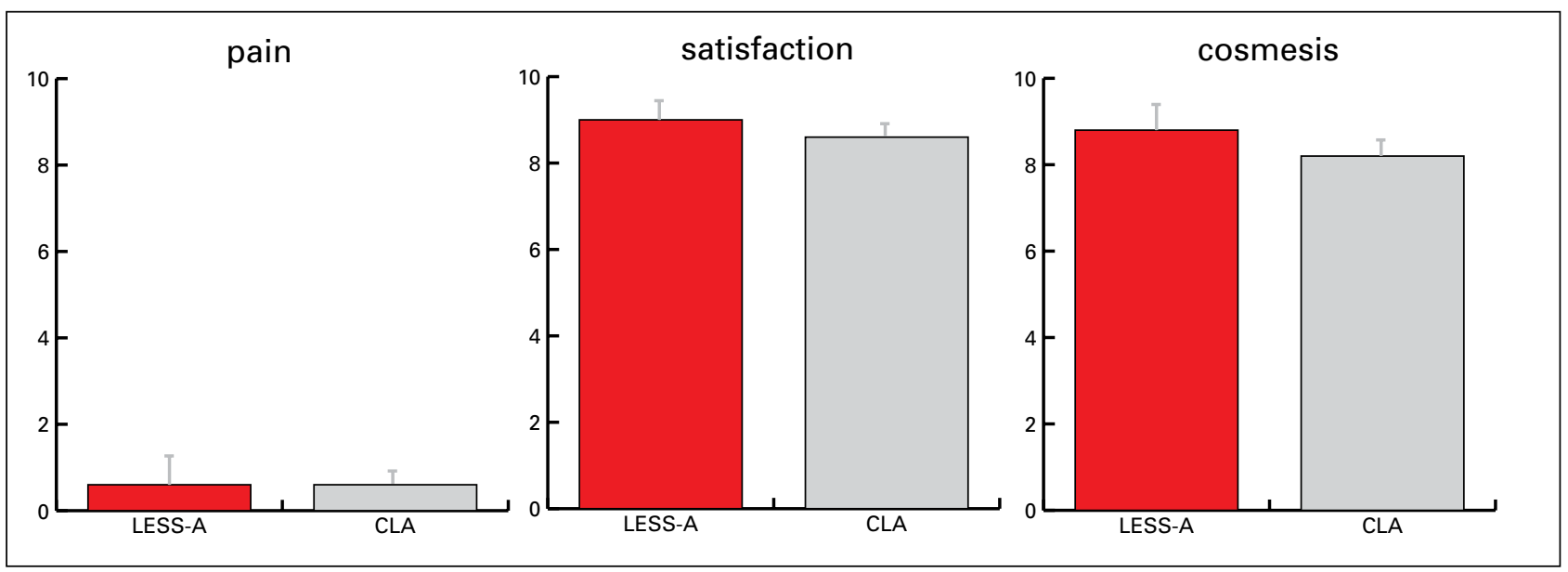

Fig. 1. Overall mean scar ratings according to surgical approach.

2a). There were no significant differences in pain or cosmesis score between the LESS-A and CLA groups for female patients. Similarly, when the patients were divided into 2 groups of younger $(<50$ years old) and older ( $\geq 50$ years old) patients, the satisfaction score for younger patients was significantly higher in the LESS-A group than in the CLA group (9.17 vs. $6.38, p=0.036$ ) (Fig. $2 b$ ). There were no significant differences in pain or cosmesis score between the LESS-A and CLA groups for younger patients. In terms of whether the procedure was carried out on the left or right

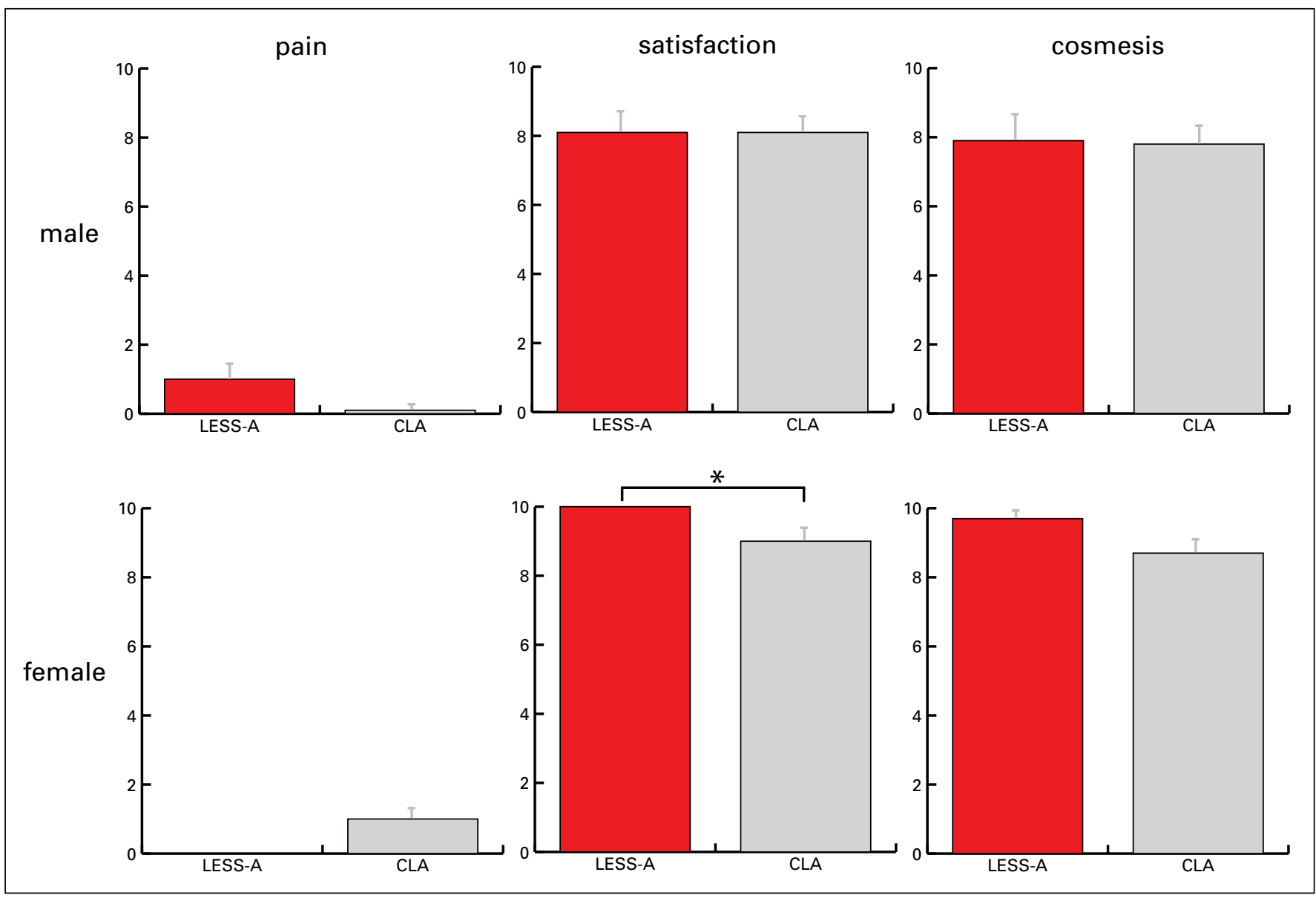

Fig. $2 a$. Results of mean scar ratings according to gender. 


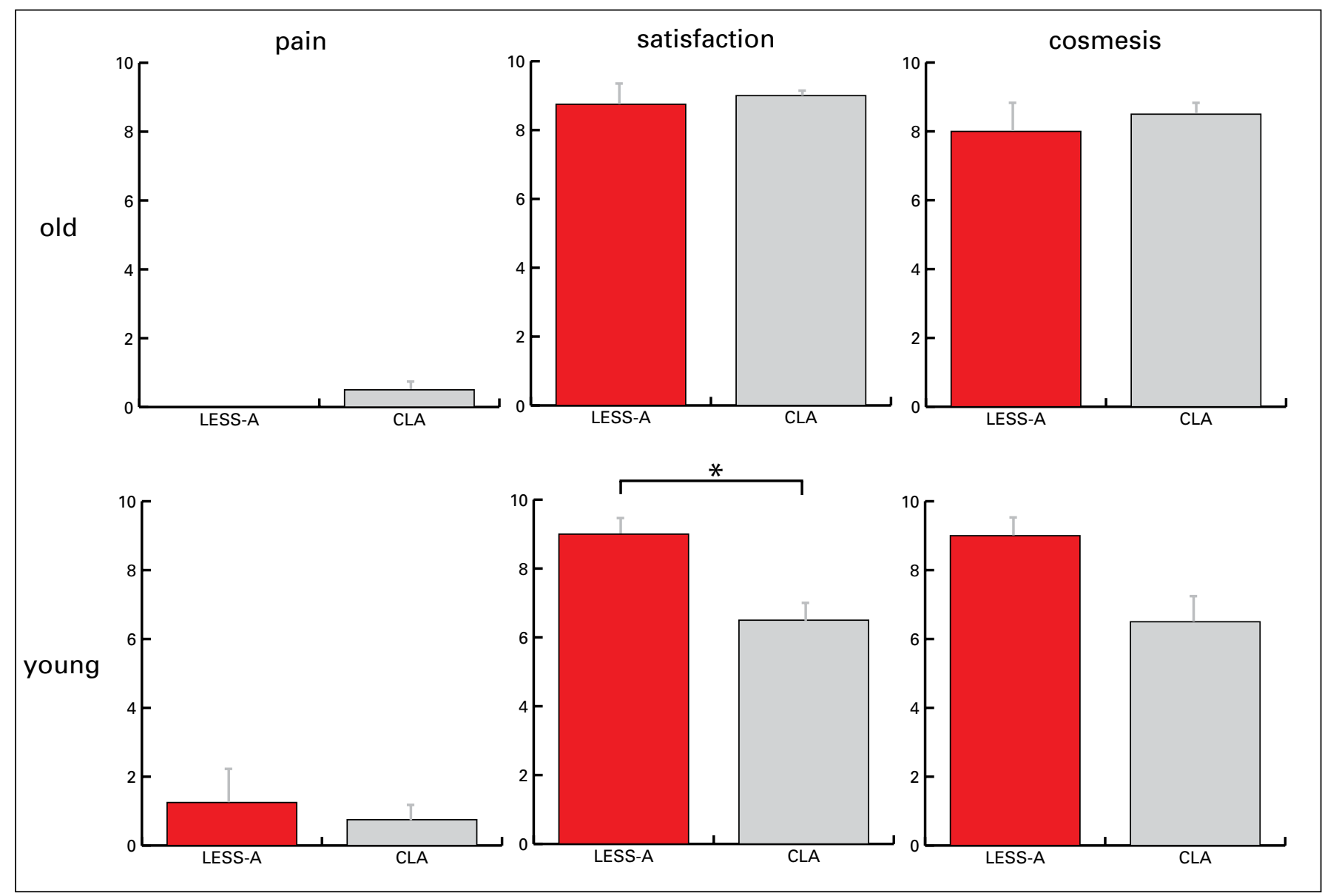

Fig. 2 b. Results of mean scar ratings according to age.

side, there were no significant differences in pain, cosmesis or satisfaction scores between the LESS-A and CLA groups.

\section{Logistic regression analysis}

Logistic regression analysis revealed that the cosmesis and satisfaction with scars is about four times more likely to rise when using LESS-A ( $p=0.176$ and $p=0.093$ ) than when using CLA, although this was not significant (Table 2a, Table 2b). Multivariate analysis for the high cosmesis and satisfaction scores showed that application of LESS-A contributed to improving cosmesis and satisfaction scores.

\section{Discussion}

Laparoscopic adrenalectomy has become the gold standard for the treatment of adrenal tumour, and it has various approaches. ${ }^{17}$ Many researchers have reported on techniques used to reduce the number of ports required to perform safe laparoscopic surgery. ${ }^{18}$ Although several efforts have been made to further reduce invasiveness in laparoscopic adrenalectomy, at the end of the procedure, an incision was mandatory for specimen retrieval. ${ }^{19}$ The most common position for access in LESS surgery has been the umbilicus for its cosmetic benefits. However, LESS-A through an umbilical access is extremely challenging due to the angle of approach and the difficulty in retracting organs. Furthermore, because the distance from the access port to the tissue is longer in the transumbilical approach than in the subcostal approach, the transumbilical approach becomes more tangential in direction in LESS-A. As the target area of dissection becomes more cranial, the difficulty of dissection using the transumbilical approach increases substantially. This raises the question of whether the subcostal approach for LESS-A provides more benefits and greater safety than the transumbilical approach - the answer to this questions is still unknown.

Previous publications have praised the cosmetic advantages of the LESS approach without objectively studying cosmesis outcomes. ${ }^{3,10-13}$ No validated studies presently exist that report patients' scar satisfaction after abdominal surgery. ${ }^{20}$ Alternatively, Park and colleagues published a study in which they comprehensively evaluated and compared cosmesis outcomes in urologic patients who under- 
Inoue et al.

\begin{tabular}{|c|c|c|c|c|}
\hline Variables & SE & $p$ value & RR & $95 \% \mathrm{Cl}$ \\
\hline Approach (LESS-A) & 0.771 & 0.093 & 3.653 & $0.805-16.57$ \\
\hline Laterality (right) & 0.578 & 0.667 & 1.282 & $0.413-3.980$ \\
\hline Gender (female) & 0.533 & 0.299 & 1.740 & $0.612-4.945$ \\
\hline Age (older) & 0.675 & 0.015 & 5.133 & $1.367-19.26$ \\
\hline
\end{tabular}

LESS-A: laparoendoscopic single-site adrenalectomy; SE: standard error; RR: relative rate; $\mathrm{Cl}$ : confidence interval.

went kidney surgery by LESS, conventional laparoscopic surgery (CLS) and open surgical approaches. They found that urologic patients favour LESS cosmesis outcomes over those for CLS or open surgery. Considering the prevailing demographic profile of the LESS group (younger, thinner and more likely to be undergoing surgery for benign diseases), they postulate that this patient subset most values the cosmetic benefits of LESS surgery. ${ }^{21}$

Lucas and colleagues reported that patients who were treated with laparoscopy for urologic diseases were predominantly concerned with complications, success, recovery and pain, and were less concerned with cosmesis. Young patients, female patients and patients who were treated for benign diseases, however, had an increased concern for cosmesis. ${ }^{22}$ This is consistent with the reports about gender differences. In the general population, men experience much less body dissatisfaction than woman. ${ }^{23,24}$ We found that with all patients, there were no significant differences in satisfaction or cosmesis scores between the LESS-A and CLA groups. However, in young and female patients, the satisfaction scores were significantly higher in the LESS group than the conventional group. Though we performed LESS-A by using the subcostal rather than the transumbilical approach, we still obtained high satisfaction, especially in young patients and female patients. This result suggests that young and female patients were less satisfied with CLA and would prefer a novel procedure, so they might be ideal candidates for LESS-A.

We acknowledge a few limitations in our study. Firstly, our research sample size was very small. Secondly, the response rate was $52.8 \%$, and therefore, our data are subject to a degree of non-response bias. Thirdly, patients were not randomized, and this study was retrospective, which may result in preferences being biased toward CLA. Fourthly, our study was cross-sectional, so the mean follow-up times after surgery were significantly shorter for LESS-A than for CLA. Further evaluation is needed in a longitudinal study to clarify whether LESS-A is superior to CLA in terms of satisfaction and cosmesis. Finally, a non-validated survey was used. Despite these limitations, we believe that our findings provide valuable insight into the value of LESS-A cosmetic outcomes to young and female urologic patients. A further prospective study with a larger number of patients will be needed to further evaluate and confirm these findings.

\begin{tabular}{|c|c|c|c|c|}
\hline Variables & SE & $p$ value & $\mathbf{R R}$ & $95 \% \mathrm{Cl}$ \\
\hline Approach (LESS-A) & 0.750 & 0.176 & 2.757 & $0.634-11.99$ \\
\hline Laterality (right) & 0.565 & 0.656 & 1.287 & $0.425-3.897$ \\
\hline Gender (female) & 0.524 & 0.887 & 1.077 & $0.386-3.009$ \\
\hline Age (older) & 0.679 & 0.045 & 3.900 & $1.030-14.76$ \\
\hline
\end{tabular}

LESS-A: laparoendoscopic single-site adrenalectomy; SE: standard error; RR: relative rate; Cl: confidence interval.

We believe that continuing advances in LESS technology will improve this surgery in the near future. ${ }^{19}$ LESS surgery should be explored with the greatest consideration placed on ethical and methodological issues. In our opinion, LESS-A is a safe technique resulting in improved cosmetic outcomes, with the additional benefit of being minimally invasive; however, long-term follow-up is necessary.

\section{Conclusions}

Young patients and female patients who had received LESS-A adrenal surgery were more satisfied with the scar outcomes than were the young patients and female patients who had received CLA.

Competing interests: Dr. Inoue, Dr. Ikeda, Dr. Kobayashi, Dr. Kajiwara, Dr. Teishima and Dr. Matsubara all declare no competing financial or personal interests.

This paper has been peer-reviewed.

\section{References}

1. Guazzoni G, Cestari A, Montorsi F, et al. Current role of laparoscopic adrenalectomy. Eur Urol 2001;40:816. hittp://dx.doi.org/10.1159/000049743

2. Raman JD, Bensalah K, Bagrodia A, et al. Laboratory and clinical development of single keyhole umbilical nephrectomy. Urology 2007;70:1039-42. htrp://dx.doi.org/10.1016/j.urology.2007.10.001

3. White WM, Haber GP, Goel RK, et al. Single-port urological surgery: Single-center experience with the first 100 cases. Urology 2009;74:801-4. http://dx.doi.org/10.1016/i.urology.2009.04.030

4. Rane A, Rao P, Rao P. Single-port-access nephrectomy and other laparoscopic urologic procedures using a novel laparoscopic port (R-port). Urology 2008;72:260-3. http://dx.doi.org/10.1016/i.urology.2008.01.078

5. Soble JJ, Gill IS. Needlescopic urology: Incorporating 2-mm instruments in laparoscopic surgery. Urology 1998:52:187-94. http://dx.doi.org/10.1016/50090-4295(98)00234-9

6. Kaouk JH, Haber GP, Goel RK, et al. Single-port laparoscopic surgery in urology: Initial experience. Urology 2008;71:3-6. hittp://dx.doi.org/10.1016/j.urology.2007.11.034

7. Desai MM, Rao PP, Aron M, et al. Scarless single port transumbilical nephrectomy and pyeloplasty: First clinical report. BJU Int 2008;101:83-8. http://dx.doi.org/10.1111/i.1464-410X.2007.07359.x

8. Raman JD, Cadeddu JA, Rao P, et al. Single-incision laparoscopic surgery: Initial urological experience and comparison with natural-orifice transluminal endoscopic surgery. BJU Int 2008;101:1493-6. http:// dx.doi.org/10.1111/i.1464-410X.2008.07586.x

9. Kaouk JH, Palmer JS. Single-port laparoscopic surgery: Initial experience in children for varicocelectomy. BJU Int 2008;102:97-9. http://dx.doi.org/10.1111/.i.1464-410X.2008.07584.x

10. Raman JD, Bagrodia A, Cadeddu JA. Single-incision, umbilical laparoscopic versus conventional laparoscopic nephrectomy: A comparison of perioperative outcomes and short-term measures of convalescence. Eur Urol 2009;55:1198-204. http://dx.doi.org/10.1016/i.eururo.2008.08.019 
11. Raybourn JH 3rd, Rane A, Sundaram CP. Laparoendoscopic single-site surgery for nephrectomy as a feasible alternative to traditional laparoscopy. Urology 2010;75:100-3. http://dx.doi.org/10.1016/i. urology.2009.05.028

12. Tugcu $V$, llbey $Y 0$, Mutlu B, et al. Laparoendoscopic single-site surgery versus standard laparoscopic simple nephrectomy: A prospective randomized study. J Endourol 2010;24:1315-20. http://dx.doi. org/10.1089/end.2010.0048

13. Desai $M M$, Berger AK, Brandina $R$, et al. Laparoendoscopic single-site surgery: Initial hundred patients. Urology 2009;74:805-12. http://dx.doi.org/10.1016/i.urology.2009.02.083

14. Canes D, Berger A, Aron M, et al. Laparo-endoscopic single site (LESS) versus standard laparoscopic left donor nephrectomy: Matched-pair comparison. Eur Urol 2010;57:95-101. http://dx.doi.org/10.1016/i. eururo.2009.07.023

15. Kurien A, Rajapurkar S, Sinha L, et al. First prize: Standard laparoscopic donor nephrectomy versus laparoendoscopic single-site donor nephrectomy: A randomized comparative study. J Endourol 201 1;25:365-70. http://dx.doi.org/10.1089/end.2010.0250

16. Zacharias $M$, Haese A, Jurczok A, et al. Transperitoneal laparoscopic adrenalectomy: Outline of the preoperative management, surgical approach, and outcome. Eur Urol 2006;49:448-59. http://dx.doi. org/10.1016/i.eururo.2006.01.014

17. McCauley LR, Nguyen MM. Laparoscopic radical adrenalectomy for cancer: Long-term outcomes. Curr Opin Urol 2008;18:134-8. http://dx.doi.org/10.1097/MOU.0b013e3282f3e6d2

18. Han WK, Park YH, Jeon HG, et al. The feasibility of laparoendoscopic single-site nephrectomy: Initial experience using home-made single-port device. Urology 2010;76:862-5. http://dx.doi.org/10.1016/i urology.2009.10.038
19. Cindolo L, Gidaro S, Neri F, et al. Assessing feasibility and safety of laparoendoscopic single-site surgery adrenalectomy: Initial experience. J Endourol 2010;24:977-80. http://dx.doi.org/10.1089/ end.2009.0535

20. Durani $P$, McGrouther DA, Ferguson MW. Current scales for assessing human scarring: A review. J Plast Reconstr Aesthet Surg 2009;62:713-20. http://dx.doi.org/10.1016/i.bips.2009.01.080

21. Park SK, Olweny E0, Best SL, et al. Patient-reported body image and cosmesis outcomes following kidney surgery: Comparison of laparoendoscopic single-site, laparoscopic, and open surgery. Eur Urol 2011;60:1097-104. http://dx.doi.org/10.1016/i.eururo.2011.08.007

22. Lucas SM, Baber J, Sundaram CP. Determination of patient concerns in choosing surgery and preference for laparoendoscopic single-site surgery and assessment of satisfaction with postoperative cosmesis. J Endourol 2012;26:585-91. http://dx.doi.org/10.1089/end.2011.0181

23. Demarest $\mathrm{J}$, Langer E. Perception of body shape by underweight average, and overweight men and women. Percept Mot Skills 1996;83:569-70. http://dx.doi.org/10.2466/pms. 1996.83.2.569

24. Lokken K, Ferraro FR, Kirchner T, et al. Gender differences in body size dissatisfaction among individuals with low, medium, or high levels of body focus. J Gen Psychol 2003;130:305-10. http://dx.doi. org/10.1080/00221300309601161

Correspondence: Dr. Shogo Inoue, Department of Urology, Graduate School of Biomedical Sciences, Hiroshima University, 1-2-3 Kasumi, Minami-ku, Hiroshima 734-8551; fax: 81-82-257-5244; inosyogo@hiroshima-u.ac.jp 